\title{
On the fast decay of Agulhas rings
}

\author{
Erik van Sebille, ${ }^{1,2}$ Peter Jan van Leeuwen, ${ }^{1,3}$ Arne Biastoch, ${ }^{4}$ \\ and Wilhelmus P. M. de Ruijter ${ }^{1}$ \\ Received 19 June 2009; revised 24 August 2009; accepted 14 October 2009; published 6 March 2010.
}

[1] The Indian Ocean water that ends up in the Atlantic Ocean detaches from the Agulhas Current retroflection predominantly in the form of Agulhas rings and cyclones. Using numerical Lagrangian float trajectories in a high-resolution numerical ocean model, the fate of coherent structures near the Agulhas Current retroflection is investigated. It is shown that within the Agulhas Current, upstream of the retroflection, the spatial distributions of floats ending in the Atlantic Ocean and floats ending in the Indian Ocean are to a large extent similar. This indicates that Agulhas leakage occurs mostly through the detachment of Agulhas rings. After the floats detach from the Agulhas Current, the ambient water quickly looses its relative vorticity. The Agulhas rings thus seem to decay and loose much of their water in the Cape Basin. A cluster analysis reveals that most water in the Agulhas Current is within clusters of $180 \mathrm{~km}$ in diameter. Halfway in the Cape Basin there is an increase in the number of larger clusters with low relative vorticity, which carry the bulk of the Agulhas leakage transport through the Cape Basin. This upward cascade with respect to the length scales of the leakage, in combination with a power law decay of the magnitude of relative vorticity, might be an indication that the decay of Agulhas rings is somewhat comparable to the decay of two-dimensional turbulence.

Citation: van Sebille, E., P. J. van Leeuwen, A. Biastoch, and W. P. M. de Ruijter (2010), On the fast decay of Agulhas rings, J. Geophys. Res., 115, C03010, doi:10.1029/2009JC005585.

\section{Introduction}

[2] The entrainment of Indian Ocean water into the Atlantic Ocean is called Agulhas leakage and its source is the Agulhas Current, the western boundary current of the Indian Ocean subtropical gyre [Gordon, 1985; Lutjeharms, 2006]. Of the volume flux carried by the Agulhas Current, however, only approximately $25 \%$ takes part in this interocean exchange. Once the Agulhas Current has detached from the continental slope, potential vorticity conservation causes the westward flowing current to retroflect. The bulk of the water in the Agulhas Current in then advected back into the Indian Ocean [De Ruijter et al., 1999].

[3] One of the reasons why Agulhas leakage is relevant is because of its role of transporting heat and salt from the Indian Ocean to the Atlantic Ocean. Once advected northward in the Atlantic Ocean, this heat and salt can influence the Atlantic meridional overturning circulation [Weijer et al., 2002; Biastoch et al., 2008b], although not all Agulhas

\footnotetext{
${ }^{1}$ Institute for Marine and Atmospheric Research, Utrecht University, Utrecht, Netherlands.

${ }^{2}$ Now at Rosenstiel School of Marine and Atmospheric Science, University of Miami, Miami, Florida, USA. UK.

${ }^{3}$ Now at Department of Meteorology, University of Reading, Reading,

${ }^{4}$ Leibniz Institute of Marine Sciences, University of Kiel, Kiel, Germany.

Copyright 2010 by the American Geophysical Union. 0148-0227/10/2009JC005585\$09.00
}

leakage crosses the equator [Donners and Drijfhout, 2004]. A large portion recirculates in the South Atlantic Ocean subtropical gyre [De Ruijter and Boudra, 1985]. This latter route is closely connected to the subtropical supergyre [Speich et al., 2002], a gyre encompassing both the Indian Ocean and the Atlantic Ocean (and possibly the Pacific Ocean too). Knorr and Lohmann [2003] and Peeters et al. [2004] have shown that the magnitude of Agulhas leakage in the southeast Atlantic Ocean is a proxy for changes in the Atlantic meridional overturning circulation. This considered, Agulhas leakage is here defined as the flux of water carried by the Agulhas Current at $32^{\circ} \mathrm{S}$ that does not retroflect back into the Indian Ocean but ends up in the Atlantic Ocean.

[4] The water which constitutes Agulhas leakage was suggested to be mainly trapped inside large anticyclones called Agulhas rings [Gordon, 1986]. These rings can be tracked in altimetry data to move into the Atlantic Ocean, while decaying and releasing their heat and salt content [Byrne et al., 1995; Beismann et al., 1999; Schouten et al., 2000; Van Aken et al., 2003; De Steur et al., 2004; Doglioli et al., 2007]. From the aggregation of these studies it appears that a typical Agulhas ring has a radius of 150 $200 \mathrm{~km}$ and that the surface velocities can exceed $1 \mathrm{~m} \mathrm{~s}^{-1}$. A ring is shed from the Agulhas Current retroflection every 2-3 months.

[5] Recently, however, it has been suggested that advection by large-scale Agulhas rings is only one of the mechanisms in which water can get from the Indian Ocean to the Atlantic 
Ocean. Boebel et al. [2003] and Matano and Beier [2003] have shown that cyclones, although they are generally smaller than the anticyclonic Agulhas rings, also play an important role in the interocean exchange. Furthermore, Treguier et al. [2003] found in a model study that more than half of the heat and salt transported by Agulhas leakage at $30^{\circ}$ $\mathrm{S}$ is not carried by eddies, but advected in smaller filaments. The important role played by filaments was also suggested by Lutjeharms and Cooper [1996].

[6] This grouping in three categories (anticyclones, cyclones, and nonrotating filaments or patches) may hold implications for the fate of temperature and salt anomalies as they enter the Atlantic Ocean. Agulhas rings have a longer life span than filaments, and can therefore advect their thermohaline properties farther into the Atlantic Ocean. As shown by Weijer et al. [2002], the response of the Atlantic meridional overturning circulation strength to Agulhas leakage sources is sensitive to the path of these thermohaline anomalies. Water that is advected within the Benguela Current rather than in Agulhas rings may end up farther north, where the chances of crossing the equator are higher [Donners and Drijfhout, 2004].

[7] Apart from the Agulhas leakage due to coherent features which have detached from the Agulhas Current, there might also be an interocean flux related to a continuous current. Gordon et al. [1995] have shown the existence of a Good Hope Jet on the continental slope in the Cape Basin. This Good Hope Jet is an intense frontal jet forced by the wind-induced upwelling at the western African coast. It is unknown what the volume transport of the jet is and what the sources of that transport are. Part of the jet will originate from the South Atlantic Ocean subtropical gyre, but there might also be a direct connection from the Indian Ocean. The inshore portion of the Agulhas Current might round the Cape of Good Hope, feeding directly into the Good Hope Jet.

[8] In a comprehensive study on the subject, Doglioli et al. [2006] have grouped Agulhas leakage into a part advected by cyclones, a part advected by anticyclones, and a part advected by the background flow. The authors have used a high-resolution model to determine the net rotation of numerical Lagrangian floats as they are advected through the Cape Basin. This was done by computing the spin parameter of each trajectory, a parameter that is related to the net curl of a trajectory throughout the entire Cape Basin. The result from this study was that $13 \%$ of the Agulhas leakage transport was due to Lagrangian floats with anticyclonic rotation, $17 \%$ of the Agulhas leakage transport was due to Lagrangian floats with cyclonic rotation, and $70 \%$ of the Agulhas leakage transport was in Lagrangian floats that had a negligible net rotation.

[9] Although the study of Doglioli et al. [2006] is very thorough, there are some caveats to using trajectories across the entire Cape Basin. The eddies in the Cape Basin can experience multiple splitting and merging events [Schouten et al., 2000; Boebel et al., 2003] and floats might enter and exit cyclones and anticyclones multiple times in their journey through the basin. This effect might be obscured when net rotation along an extended section of the float's path is computed because a float which is in an anticyclone for half of its journey before being trapped in a cyclone may have a very small net curl. In combination with the relatively low number of floats used, this makes the results of Doglioli et al. [2006] uncertain.

[10] The apparent discrepancy between studies reporting that Agulhas rings are the dominant agent of leakage and studies finding that Agulhas leakage is mainly in nonrotating filaments may be due to the location where the Agulhas leakage transport is measured. Both Byrne et al. [1995] and Schouten et al. [2000] have shown that Agulhas rings experience decay after they have spawned from the Agulhas Current retroflection. Byrne et al. [1995] report a $1700 \mathrm{~km}$ $e$-folding distance when rings were tracked in space and Schouten et al. [2000] observe a fast decay in the first 10 months when rings were tracked in time. It might therefore be that the results of grouping Agulhas leakage in anticyclones, cyclones, and nonrotating filaments depend on how far away from the Agulhas Current retroflection the grouping is performed.

[11] Although the studies of Byrne et al. [1995] and Schouten et al. [2000] have provided a lot of insight on the temporal and spatial scales of Agulhas ring decay, there are several questions that these studies have not been able to answer. First of all, it is unclear what happens with the debris of Agulhas rings, the water which was initially trapped in the rings. De Steur et al. [2004] suggested that this debris forms initially in filaments, but did not study their fate. Furthermore, the dynamical behavior soon after a ring has been shed is still unknown, as the tracking technique in satellite data used by Byrne et al. [1995] and Schouten et al. [2000] does not work when the Agulhas rings are still close to the Agulhas Current retroflection.

[12] In this study we will use a time series of numerical Lagrangian float trajectory data to address the characteristics of the water which forms Agulhas leakage. After introducing the model setup (section 2), we will investigate how and where the bifurcation of Agulhas leakage and Agulhas Return Current water is controlled, by grouping the floats by the ocean in which they end up (section 3). Then, the decay of rotating features will be examined by analyzing the relative vorticity of the water as the floats detach from the Agulhas Current (section 4). Finally, we will investigate what the decrease in relative vorticity does to the size of the coherent features (section 5).

\section{Model}

[13] The magnitude of Agulhas leakage is in this study estimated from the transport as sampled by numerical Lagrangian floats which are seeded in the Agulhas Current. The Lagrangian floats are advected using three-dimensional 5 day averaged velocity fields from the AG01 model [Biastoch et al., 2008a, 2008b]. This is a $1 / 10^{\circ}$ numerical ocean model of the Agulhas region $\left(20^{\circ} \mathrm{W}-70^{\circ} \mathrm{E} ; 47^{\circ} \mathrm{S}-7^{\circ} \mathrm{S}\right)$ based on the NEMO code (version 2.3 [Madec, 2006]). The model has 46 vertical layers, with layer thicknesses ranging from $6 \mathrm{~m}$ at the surface to $250 \mathrm{~m}$ at depth. The model employs partial cells at the ocean floor for a better representation of bathymetry.

[14] The regional AG01 model is nested within a global model, ORCA, a $1 / 2^{\circ}$ global ocean-sea-ice model which is also based on NEMO. The two-way nesting allows for information exchange between the two models [Debreu et al., 2008]. Not only are the boundary conditions of the high- 

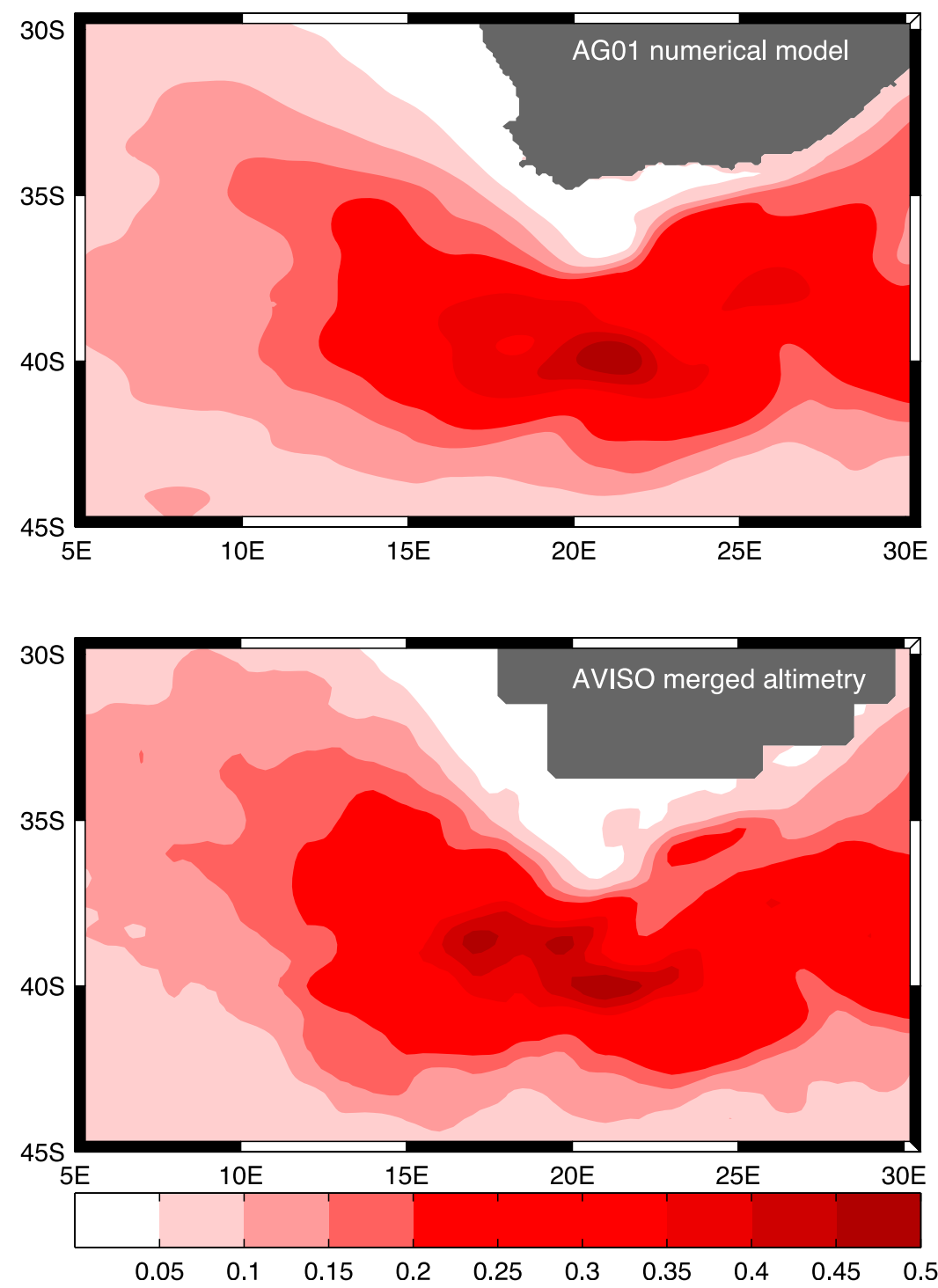

Figure 1. The root-mean-square variability in sea surface height in the Cape Basin (top) in the AG01 model and (bottom) in the AVISO altimetry data, in $\mathrm{m}$ on the same scale. The modeled variability in the Cape Basin is generally of the right magnitude in the model, although the small-scale variability is somewhat underestimated in the model.

resolution AG01 model taken from the low-resolution ORCA model, but the low-resolution ORCA model also gets updated by the high-resolution AG01 model at shared grid points. The Agulhas region dynamics is therefore affected by the global circulation, and vice versa. In this approach, the two models have to be run simultaneously. The two models are forced with the CORE data set of daily wind and surface forcing fields [Large and Yeager, 2004] for the period 1958-2004. The model is spun up for 10 years, which leaves a 37 year time series at 5 day resolution (1968-2004) for Eulerian analysis.

[15] The AG01 model is the model that comes best out of the three-model quantitative skill assessment [Van Sebille et al., 2009b]. Furthermore, a comparison of the modeled sea surface height variability to the root-mean-square variability from satellite altimetry (Figure 1) shows that the model performs reasonably in the Cape Basin, the area where the Agulhas rings experience most decay. The altimetry data used is from the AVISO project: More than 15 years of weekly merged sea level anomalies in the Agulhas region on a $1 / 4^{\circ}$ resolution, combined with the Rio and Hernandez [2004] mean dynamic topography (http://www.aviso.oceanobs.com/ duacs/).

[16] The trajectories of the numerical Lagrangian floats are integrated using the ARIANE package [Blanke and Raynaud, 1997]. Floats are released every 5 days in a $300 \mathrm{~km}$ zonal section of the Agulhas Current at $32^{\circ} \mathrm{S}$. The number of floats which are released at a particular moment is based on the 5 day average transport per grid cell, with only floats released when the velocity in the grid cell is southward. Each float represents a certain transport, with a maximum of $0.1 \mathrm{~Sv}$. Using the 5 day mean velocity fields, the floats are advected for a maximum of 5 years. When a float hits one of the trajectory boundaries, the integration of that float is stopped. These trajectory boundaries are at $32^{\circ} \mathrm{S}$ and $40^{\circ} \mathrm{E}$ in the Indian Ocean, at $47^{\circ} \mathrm{S}$ in the Southern Ocean, 


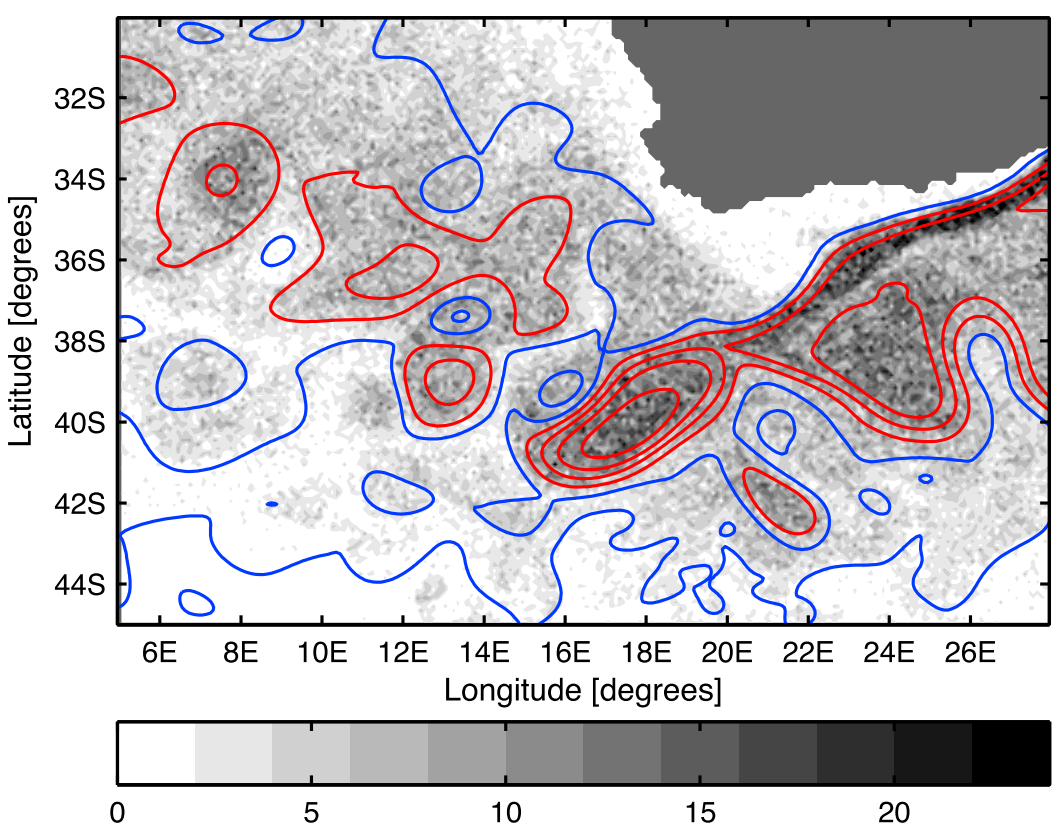

Figure 2. The number of floats per grid cell in the model run on 6 December 1996. In total, there are $1.5 \times 10^{6}$ floats in this subdomain of the high-resolution nested model. The lines denote the instantaneous sea surface height (at a contour interval of $25 \mathrm{~cm}$ ), with negative values in blue and positive values in red. The features in this snapshot are typical for the model. Although there are large variations in the density of floats, with enhanced concentrations in the Agulhas Current and Agulhas rings (the closed contours in the northwestern corner), most of the Agulhas region is sampled by the numerical floats. There are almost no dynamically active regions (eddies and other regions with large gradients in sea surface height) that are not sampled by the floats.

and at $5^{\circ} \mathrm{S}$ and $20^{\circ} \mathrm{W}$ in the Atlantic Ocean. The floats are isopycnal, which means that they are not bound to a particular model layer. At any moment in the model run, the number of floats in the model is in the order of $5 \times 10^{5}$, and the amount of floats within a grid cell can get as high as 30 (Figure 2). Biastoch et al. [2008a, 2008b] have used the same model and Lagrangian techniques to simulate Agulhas Current transport and Agulhas leakage.

[17] In the 37 year period, $5.6 \times 10^{6}$ floats are released, which constitutes a mean Agulhas Current transport at $32^{\circ} \mathrm{S}$ of $64 \mathrm{~Sv}$. On the 5 day resolution, however, the Agulhas Current strength ranges from $30 \mathrm{~Sv}$ to $128 \mathrm{~Sv}$. As shown by Biastoch et al. [2009], the strength of the Agulhas Current in the model is in agreement with over a year of in situ measurements by Bryden et al. [2005], who report an Agulhas Current range from $9 \mathrm{~Sv}$ to $121 \mathrm{~Sv}$, with a mean of $70 \mathrm{~Sv}$. After the 5 year integration period, only $3 \%$ of the numerical floats have not exited the domain. The mean magnitude of Agulhas leakage in the model is $16.7 \mathrm{~Sv}$. This is higher than the $12 \mathrm{~Sv}$ mean of Agulhas leakage in the study of Biastoch et al. [2008b], which was based on the same model but used only the first 4 years of the float data set.

[18] A float contributes to the Agulhas leakage transport when it ends in the Atlantic Ocean. The transport which the float represents is added to the time series of Agulhas leakage when the float crosses the Good Hope line for the last time. The Good Hope line is a virtual section between South Africa and Antarctica in the Atlantic Ocean (Figure 3). The line currently serves as an XBT section [Swart et al., 2008] and between 2003 and 200512 Pressure Inverted Echo Sounders have been deployed on the line in the ASTTEX program [Byrne and McClean, 2008]. The line runs right through the Cape Basin, which is known for its vigorous stirring and mixing of mesoscale eddies [Boebel et al., 2003]. After a short $250 \mathrm{~km}$ zonal excursion, the section follows a southwestward oriented TOPEX/POSEIDON-JASON1 ground track.

[19] By categorizing the floats on the basis of the ocean in which they end, the aptness of the Good Hope line for measuring the magnitude of Agulhas leakage can be demonstrated (Figure 3). On the one hand, the flux through the Good Hope line by numerical floats that end in the Indian Ocean is negligible. Spurious fluxes from water that retroflects back into the Indian Ocean are therefore small. On the other hand, the Good Hope line is still close to the Agulhas Current retroflection, so that the time lag between a float separating from the Agulhas Current and crossing the line is not too large. Note that this does not mean that the fluxes over the Good Hope line are exclusively Agulhas leakage as there are also fluxes of water crossing the line which originate from the South Atlantic Ocean subtropical gyre and the Antarctic Circumpolar Current.

\section{Upstream Control of Float Fate}

[20] The ratio between floats ending up in the Atlantic Ocean and floats ending up in the Indian Ocean is roughly $1: 3$. That means that a float has an approximately $25 \%$ chance of ending in the Atlantic Ocean, which is the same number as found by Richardson [2007] using real drifters and floats. The 

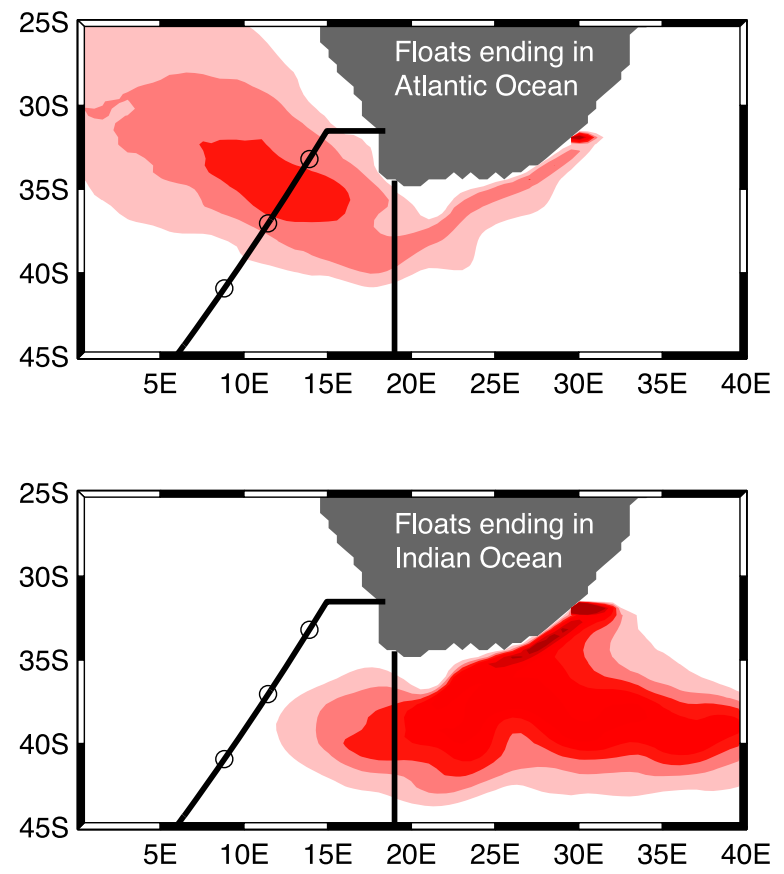

Figure 3. The density of the numerical float trajectories for (top) floats that end up in the Atlantic Ocean and (bottom) floats that end of in the Indian Ocean, in Sv on the same scale. The density is calculated on a $0.5^{\circ} \times 0.5^{\circ}$ grid. The thick black lines in the Atlantic Ocean denote the location of the Good Hope line, with the circles the positions of the 500,1000 , and $1500 \mathrm{~km}$ offshore points. The lines at $19^{\circ} \mathrm{E}$ are an indication of the mean Agulhas Current retroflection position. The vast majority of floats that cross the Good Hope line end up in the Atlantic Ocean, making it a suitable section for measuring the magnitude of Agulhas leakage.

question is whether that probability is uniform over the entire Agulhas Current or whether there is a bias based on the across-current position and path of the float within the current. This question is related to the problem of how floats are 'leaked' into the Atlantic Ocean. One may propound two mechanisms by which Agulhas leakage is separated from water that recirculates in the Indian Ocean.

[21] In the first mechanism, the water is disentangled based on its offshore distance and thus the float fate also depends on the offshore distance. At the Agulhas Current retroflection, there could be a bifurcation of the flow with the inshore part of the current core flowing predominantly into the Atlantic Ocean and the offshore part retroflecting into the Indian Ocean. The gain of shear-generated cyclonic relative vorticity on the inshore side of the current core could aid in steering the inshore part of the Agulhas Current into the Atlantic Ocean, while the retroflection of the offshore part could be aided by the excess anticyclonic vorticity. Beal and Bryden [1999] have shown from observations of the Agulhas Current core at $32^{\circ} \mathrm{S}$ that such a structure of the relative vorticity (cyclonic on the inshore side, anticyclonic on the offshore side) is indeed present in the Agulhas Current, as is expected in any western boundary current.

[22] In the second mechanism, Agulhas leakage occurs mainly through mesoscale ring shedding events. This mechanism is essentially the loop occlusion mechanism, as proposed by $\mathrm{Ou}$ and De Ruijter [1986] and further discussed by Lutjeharms and Van Ballegooyen [1988] and Feron et al. [1992]. When the Agulhas Current connects to the Agulhas Return Current east of the retroflection location, a shortcut is formed. The remains of the retroflection west of the shortcut detach from the Agulhas Current and can move into the Atlantic Ocean. Due to the anticyclonic rotation which is still present, these remains form an Agulhas ring. The exact timing of these rings shedding events seems to be related to the arrival of inshore perturbations (so-called Natal pulses) into the Agulhas Current retroflection region [Lutjeharms and Roberts, 1988; Van Leeuwen et al., 2000].

[23] The similar distributions for the two float categories within the Agulhas Current core at $19^{\circ} \mathrm{E}$ (Figure 4) are evidence for the ring shedding event mechanism and not so much for the current bifurcation mechanism since the distributions would then be more disjunct. Nevertheless, the inshore side of the Agulhas Current does possess cyclonic relative vorticity (Figure 4) but this cyclonic vorticity is apparently not sufficient to have a large influence on the Agulhas Current retroflection. This is not very remarkable, as the Agulhas system is controlled by planetary vorticity and stretching rather than relative vorticity [Boudra and Chassignet, 1988].

[24] These similar distributions of retroflected and leaked floats are interesting in view of the results by Beal et al. [2006]. These authors showed, based on hydrographic sections, that the Agulhas Current is not well mixed with respect to its source waters. There are basically two pathways into the Agulhas Current: through the Mozambique Channel and south of Madagascar. Beal et al. [2006] found that the waters which flow through the Mozambique Channel are located predominantly on the inshore side of the Agulhas Current, while the water masses from south of Madagascar stay predominantly on the offshore side. This implies that in the Atlantic Ocean there would be a bias toward Mozambique Channel water when the chance for a float to end up in the Atlantic Ocean is higher on the inshore side of the current. But since that chance to end up in the Atlantic Ocean seems to be more or less uniform across the Agulhas Current, the bias in different source water masses in Agulhas leakage is probably small.

[25] However, there might be a minor role played by the current bifurcation mechanism. Close to the coast, on the Agulhas Bank, there is a secondary core of Agulhas leakage water (Figure 4). This core consists of floats within water of cyclonic relative vorticity that have detached from the Agulhas Current more upstream (Figure 5). The mean transport sampled by floats that cross $19^{\circ} \mathrm{E}$ north of $36^{\circ} \mathrm{S}$ is only $2 \mathrm{~Sv}$, in contrast to the more than $14 \mathrm{~Sv}$ transported south of that latitude. Nevertheless, the coastal core is a persistent and continuous feature (not shown).

[26] The coastal core might be related to the Good Hope Jet, a frontal boundary current feeding into the Benguela Current [Bang and Andrews, 1974; Gordon et al., 1995]. According to Fennel [1999], the current is formed by trapping of coastal Kelvin waves on the thermal front created by the Benguela upwelling. It appears that much of the water in the coastal shelf core at $19^{\circ} \mathrm{E}$ feeds directly into the Good Hope Jet (Figure 6), as almost half of the floats within the shelf core at $19^{\circ} \mathrm{E}$ cross the Good Hope line at a maxi- 


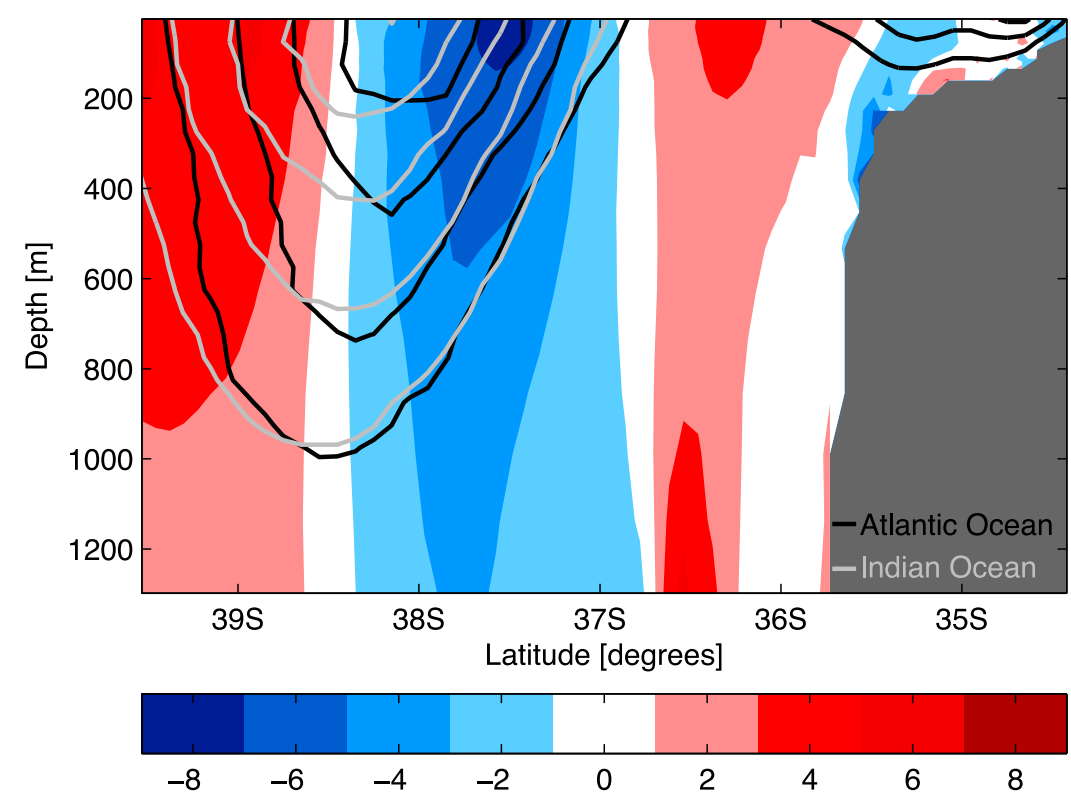

Figure 4. The location of float crossings at $19^{\circ} \mathrm{E}$ for floats that end up in the Atlantic Ocean (black contours) and floats that up end in the Indian Ocean (gray contours). The contour interval is $0.1 \%$ of the total transport per category. The colored patches show the time-averaged relative vorticity at this longitude, in $10^{-6} \mathrm{~s}^{-1}$. At $19^{\circ} \mathrm{E}$, the current has detached from the continental slope [Van Sebille et al., 2009a]. Except for the small core of water ( $2 \mathrm{~Sv}$ ) containing only floats that end in the Atlantic Ocean over the Agulhas Bank, the distributions are to a large extent similar, especially on the inshore side of the Agulhas Current where the mean relative vorticity is cyclonic. This is an indication for the loop occlusion mechanism as the main mechanism controlling Agulhas leakage.

mum offshore distance of $200 \mathrm{~km}$. In this numerical model, therefore, there is a small but significant amount of direct and continuous Agulhas leakage over the Agulhas Bank, feeding into the Good Hope Jet.

\section{Decay of Relative Vorticity}

[27] In the previous section it has been shown that within the model it seems that leakage from the Agulhas Current occurs predominantly through the loop occlusion mechanism and Agulhas ring detachment. However, Doglioli et al. [2006] found that within the Cape Basin the transport by floats with anticyclonic curl is only a small fraction of all Agulhas leakage. These two results could be connected if the Agulhas rings decay before they reach the Cape Basin. The water will then loose its relative vorticity and the floats will stop spinning. To test this hypothesis, the relative vorticity of the water at the locations where the floats cross

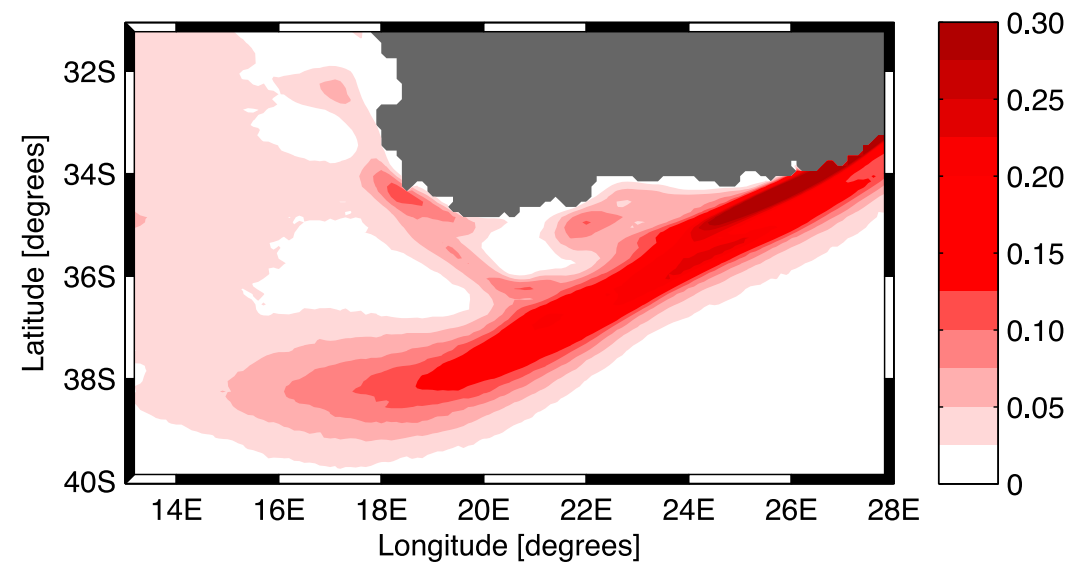

Figure 5. A map of the float trajectories in the uppermost model layer for floats that end in the Atlantic Ocean. For each longitude, the distribution of the latitude where the floats cross that longitude is shown, in $10^{-6} \mathrm{~Sv} \mathrm{~m}^{-2}$. Most floats are advected within the Agulhas Current core until $19^{\circ} \mathrm{E}, 38^{\circ} \mathrm{S}$, but there is also a direct connection into the Atlantic Ocean over the Agulhas Bank that bifurcates from the Agulhas Current east of $20^{\circ} \mathrm{E}$. 


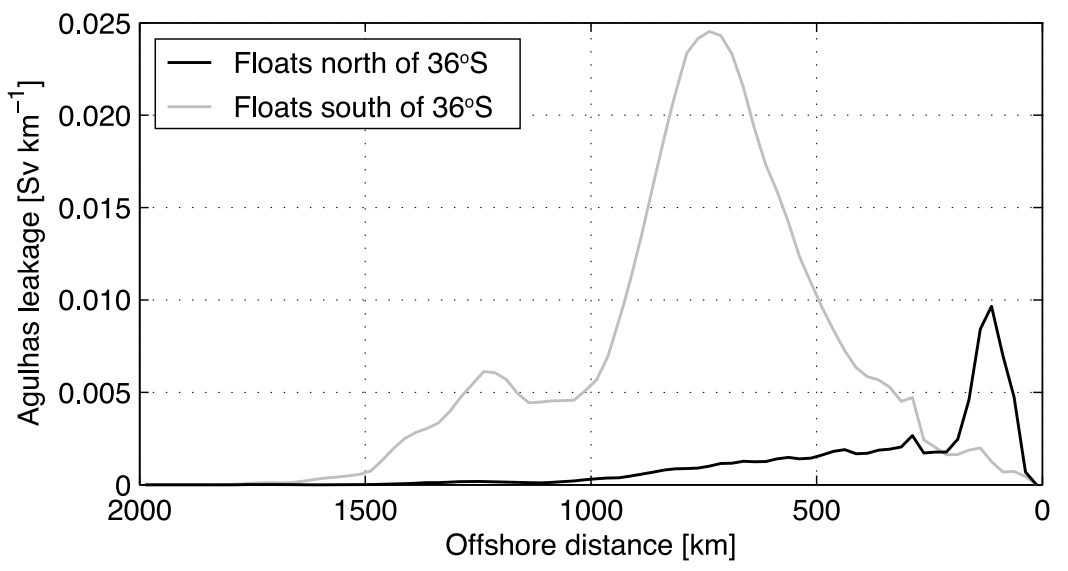

Figure 6. The distribution of Agulhas leakage as a function of offshore distance at the Good Hope line for floats that cross $19^{\circ} \mathrm{E}$ north of $36^{\circ} \mathrm{S}$ (black line) and floats that cross it south of $36^{\circ} \mathrm{S}$ (gray line). The latitude of $36^{\circ} \mathrm{S}$ separates floats in the Agulhas Current core from floats in the shallow continental shelf core (see Figure 4). Almost half of the floats in the continental shelf core stay within $200 \mathrm{~km}$ of the coast, which is the location of the Good Hope Jet [Bang and Andrews, 1974]. Of the floats in the Agulhas Current core, on the other hand, only a minor fraction crosses the Good Hope line near the coast.

$19^{\circ} \mathrm{E}$ is compared to the relative vorticity of the water at the locations where the floats cross the Good Hope line. Only floats that end in the Atlantic Ocean and cross $19^{\circ} \mathrm{E}$ south of $36^{\circ} \mathrm{S}$ are considered, as the floats north of $36^{\circ} \mathrm{S}$ seem to have a different leakage mechanism and are associated with the Good hope Jet instead of Agulhas rings.

[28] Employing the relative vorticity of the ambient water around a float, as is done here, is a very different method of discerning Agulhas rings and Agulhas cyclones than that used by Doglioli et al. [2006] and also Richardson [2007]. These authors have studied the spinning or looping of individual tracks (a Lagrangian method) whereas the focus here is on the properties of the water around the floats (a Eulerian method), see also section 7. Regrettably, thus, the results presented here cannot directly be related to the results by Richardson [2007] obtained from analysis of the looping characteristics of real ocean drifters and floats. However, the skill of the model trajectories themselves, using the same real ocean data set, has already been assessed [Van Sebille et al., 2009b].

[29] Between $19^{\circ} \mathrm{E}$ and the Good Hope line the floats move into water with much smaller relative vorticity (Figure 7). The tails of the relative vorticity distribution collapse on the journey through the Cape Basin. Within the Agulhas Current core at $19^{\circ} \mathrm{E}$, the distribution of relative vorticity is skewed and peaks at $5 \times 10^{-6} \mathrm{~s}^{-1}$. At the Good Hope line, however, the distribution of relative vorticity peaks at zero and is nearly symmetric around that peak.

[30] In order to compare the distributions of this relative vorticity analysis with the results from Doglioli et al. [2006], the floats have to be categorized in cyclonically, anticyclonically, and nonrotating water. We do this by

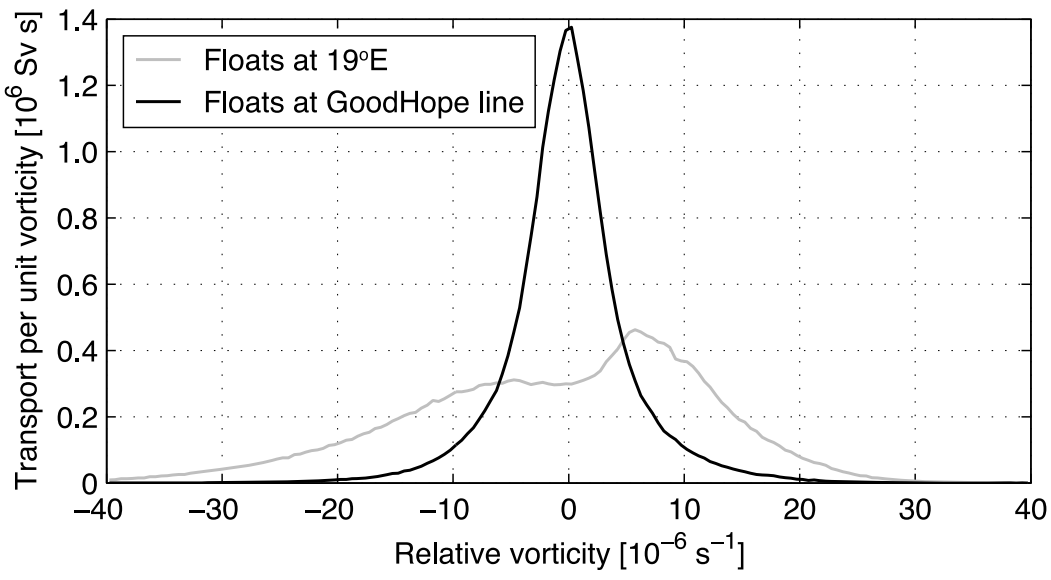

Figure 7. The distribution of Agulhas leakage as a function of relative vorticity for floats that cross $19^{\circ} \mathrm{E}$ south of $36^{\circ} \mathrm{S}$, as they cross $19^{\circ} \mathrm{E}$ (gray line) and as they cross the Good Hope line (black line). The areas under the two distributions are equal, since only the floats that end in the Atlantic Ocean are used and each float that crosses $19^{\circ} \mathrm{E}$ also crosses the Good Hope line. At $19^{\circ} \mathrm{E}$, the magnitude of relative vorticity is high, and on their path toward the Good Hope line the floats loose that relative vorticity. 
Table 1. Float-Determined Agulhas Leakage Transport ${ }^{\mathrm{a}}$

\begin{tabular}{lccc}
\hline & At $19^{\circ} \mathrm{E}$ & $\begin{array}{c}\text { At the Good } \\
\text { Hope Line }\end{array}$ & $\begin{array}{c}\text { By Doglioli et al. } \\
{[2006]}\end{array}$ \\
\hline Cyclonic motion & 5.0 & 2.7 & 2.5 \\
Nonrotating water & 1.8 & 6.8 & 10.1 \\
Anticyclonic motion & 5.3 & 2.6 & 1.9
\end{tabular}

${ }^{\mathrm{a}}$ The float-determined Agulhas leakage transport is given in Sverdrup and for different categories of floats within the Agulhas Current core at $19^{\circ} \mathrm{E}$, at the Good Hope line, and from the study by Doglioli et al. [2006] using the net spin of trajectories in the Cape Basin. Note that the total magnitude of Agulhas leakage in this study is lower than that in the study by Doglioli et al. [2006] because floats in the Good Hope Jet have been disregarded here. Although the way in which the transports are determined differ between this study and that of Doglioli et al. [2006], the results in the Cape Basin are comparable. More than half of the transport is in nonrotating water and the rest of the water is equipartitioned between cyclonic and anticyclonic rotation. Within the Agulhas Current core at $19^{\circ} \mathrm{E}$ on the other hand, most floats have a significant rotation.

choosing a critical vorticity $\zeta_{c r i t}=3 \times 10^{-6} \mathrm{~s}^{-1}$ that divides Agulhas leakage into cyclonic $\left(\zeta<-\zeta_{\text {crit }}\right)$, nonrotating $\left(-\zeta_{\text {crit }} \leq \zeta \leq \zeta_{\text {crit }}\right)$, and anticyclonic leakage $(\zeta>$ $\left.\zeta_{\text {crit }}\right)$. The choice for $\zeta_{\text {crit }}=3 \times 10^{-6} \mathrm{~s}^{-1}$ comes from the study by Van Aken et al. [2003]. These authors measured the properties of Agulhas ring 'Astrid' and reported values for relative vorticity in the upper $1000 \mathrm{~m}$ between $5 \times 10^{-6}$ and $20 \times 10^{-6} \mathrm{~s}^{-1}$. However, since this minimum relative vorticity value of $5 \times 10^{-6}$ coincides exactly with the peak in relative vorticity distribution in Figure 7 , the critical vorticity is chosen somewhat lower, without the main conclusions changing.
[31] The categorization using $\zeta_{c r i t}=3 \times 10^{-6} \mathrm{~s}^{-1}$ leads to comparable results at the Good Hope line as the categorization procedure used by Doglioli et al. [2006] in the entire Cape Basin (Table 1, note that these numbers depend on the choice for $\left.\zeta_{c r i t}\right)$. At the Good Hope line, approximately $70 \%$ of Agulhas leakage is in water with negligible relative vorticity. Near the retroflection, at $19^{\circ} \mathrm{E}$, on the other hand, leakage is much more equipartitioned between the three categories.

[32] In order to investigate the transformation of high relative vorticity leakage to much lower relative vorticity leakage, the floats that cross $19^{\circ} \mathrm{E}$ south of $36^{\circ} \mathrm{S}$ are tracked until they reach the Good Hope line. In contrast to the relative vorticity analysis above, which was done by twodimensional interpolation of relative vorticity on the location where floats crossed the Good Hope line or the $19^{\circ} \mathrm{E}$ section, the relative vorticity of the floats is now tracked in time. Every 5 days during their migration toward the Good Hope line, the relative vorticity of the water at the location of the float is determined by a three-dimensional linear interpolation. Only the first 10 years of the model output are used, which yields $3.2 \times 10^{5}$ trajectories with a mean length of 120 days. This implies that on average the journey from $19^{\circ} \mathrm{E}$ to the Good Hope line takes 120 days.

[33] The change in relative vorticity appears to be closely related to the decay of Agulhas rings after they are shed from the Agulhas Current retroflection (Figure 8). The decay rate of the magnitude (the absolute value) of relative vorticity over all floats in the Agulhas Current core at $19^{\circ} \mathrm{E}$ that end up in the Atlantic Ocean is comparable to the mean decay rate found by Schouten et al. [2000]. These

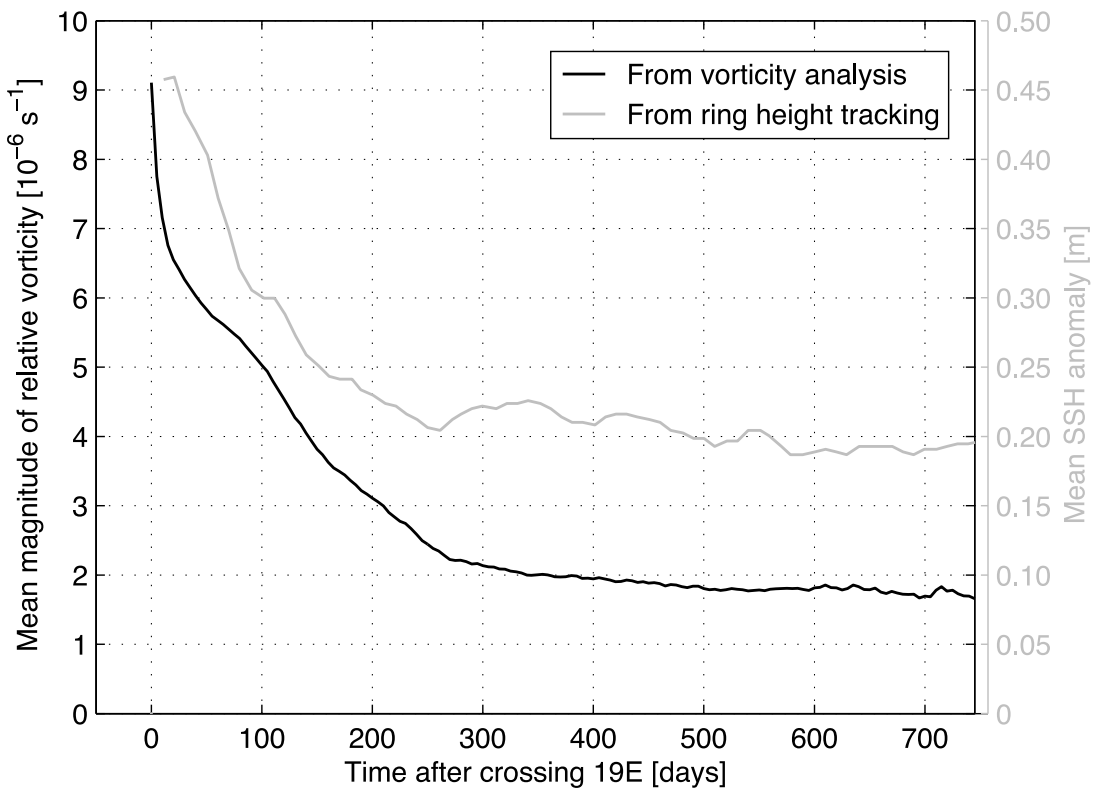

Figure 8. The mean magnitude of relative vorticity as a function of time as the floats move from $19^{\circ} \mathrm{E}$ to the Good Hope line (black line, left axis). Only floats between these two lines are considered, so the amount of floats used in this analysis decreases with time as the floats cross the Good Hope line. The gray line (right axis) shows the decay rate of Agulhas rings, as found by Schouten et al. [2000] from satellite altimetry. Note that the relative timing of the two lines is not exact, as the tracking of Agulhas rings generally started westward of $19^{\circ} \mathrm{E}$. Nevertheless, the decay rates are to a large extent comparable, which is somewhat remarkable given that the two are very different measures of ring decay. 

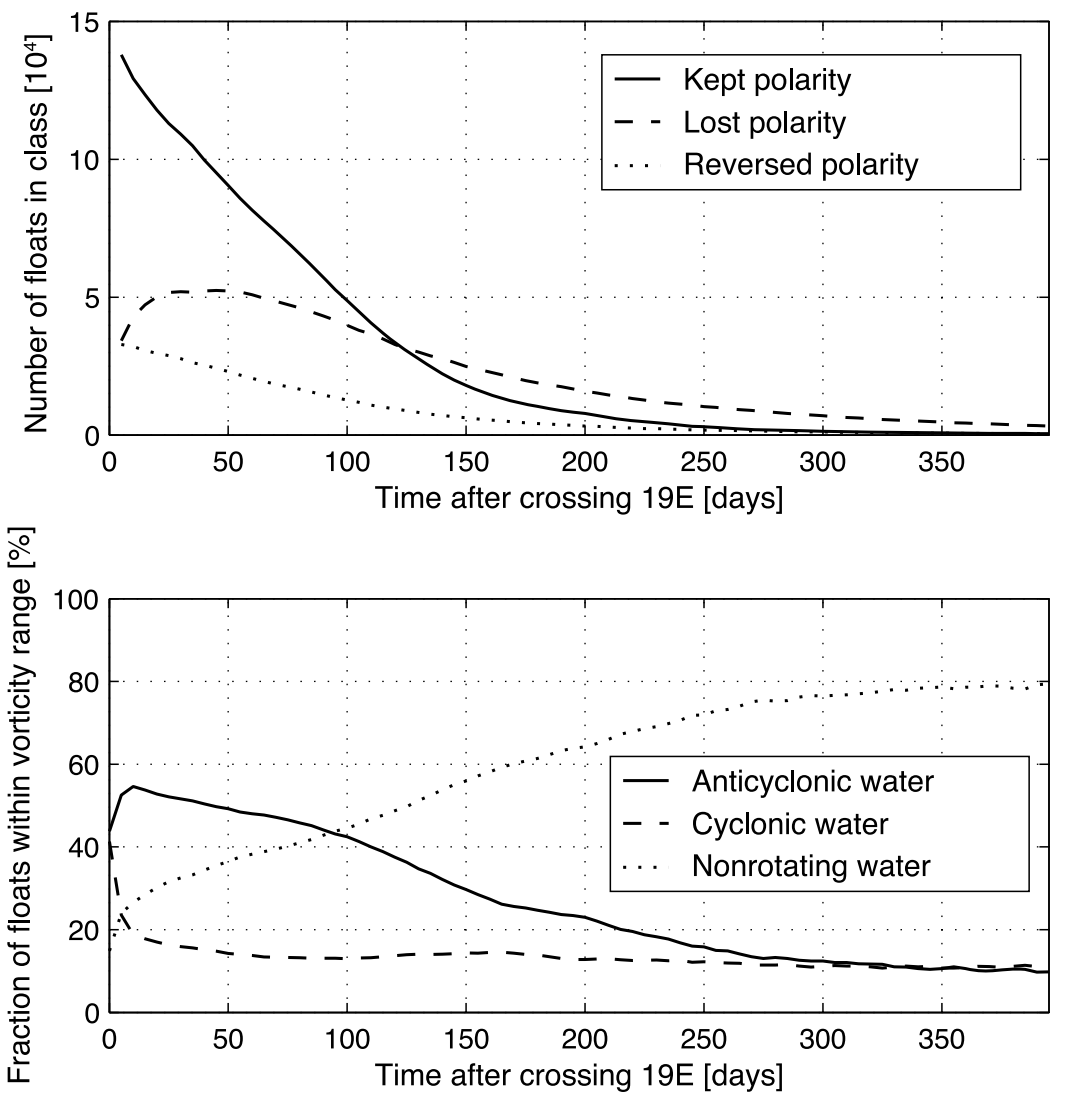

Figure 9. (top) The number of floats grouped based on the evolution of their polarity (positive for anticyclonic motion and negative for cyclonic motion) as they move from $19^{\circ} \mathrm{E}$ to the Good Hope line. The number of floats that keep their polarity (either positive or negative, solid line) decays much faster than the number of floats that loose their polarity (dashed line) or reversed polarity (dotted line). (bottom) Another way to view this is to study the fraction of floats within a certain vorticity category as a function of time as the floats move from $19^{\circ} \mathrm{E}$ to the Good Hope line. The floats are grouped in anticyclonically rotating water $\left(\zeta>\zeta_{\text {crit }}\right.$, solid line), cyclonically rotating water $\left(\zeta<-\zeta_{\text {crit }}\right.$, dashed line), and nonrotating water $\left(-\zeta_{\text {crit }} \leq \zeta \leq \zeta_{\text {crit }}\right.$, dotted line), with $\zeta_{\text {crit }}=3 \times 10^{-6} \mathrm{~s}^{-1}$. At any moment, the sum of the three lines is $100 \%$. At $19^{\circ} \mathrm{E}$, the floats are approximately equally partitioned over the classes with significant rotation (see Table 1), and as they move into the Cape Basin a considerable amount of floats in anticyclonic water and cyclonic water move into water with a low magnitude of relative vorticity. Note that the fraction of floats in cyclonic water appears to decay much faster than the fraction of floats in anticyclonic water.

authors tracked 21 Agulhas rings in satellite altimetry and recorded their maximum height anomaly. In both studies the decay of Agulhas rings decreases after approximately 10 months. It is somewhat surprising that the decay rates are so similar, as the two curves in Figure 8 are obtained by a very different method for estimating ring decay.

[34] The fraction of floats within cyclonically rotating water appears to reduce much faster than the fraction of floats within anticyclonically rotating water (Figure 9). Within 300 days, almost $80 \%$ of the floats are within water with low magnitudes of relative vorticity (using the $\zeta_{\text {crit }}=$ $3 \times 10^{-6} \mathrm{~s}^{-1}$ categorization). But where the decrease of water with anticyclonic vorticity is almost linear over that period, the fraction of water with cyclonic vorticity approximately halves within the first month. These conclusions are not sensitive to the choice of $\zeta_{c r i t}$, although the exact numbers in Table 1 and Figure 7 are. For $\zeta_{\text {crit }}>1.5 \times 10^{-6} \mathrm{~s}^{-1}$ the number of floats in anticyclonically rotating water decays linearly within 300 days, the number of floats in cyclonically rotating water decays within a month, and the number of floats in nonrotating water grows to more than $60 \%$.

[35] A small fraction of this decrease of the number of floats within water with cyclonic vorticity might be the result of the divergence of the flow on the surface of the cyclones, expelling the floats. However, the time scale is so short that the decay of Agulhas cyclones themselves must play an important role too. The point that expelling of floats from eddies is only of minor influence can also be observed in Figure 2, where most of the cyclones and Agulhas rings have relatively high float densities even beyond the Good Hope line. One explanation for the faster decay of water with cyclonic relative vorticity might be that some of this water is situated at the edges of Agulhas rings. Therefore, it might be peeled off first when the rings decay.

[36] If it is assumed that the sum of planetary and relative vorticity is conserved (so neglecting stretching in the potential vorticity balance), the northward migration of Agulhas rings and cyclones leads to an increase in planetary 


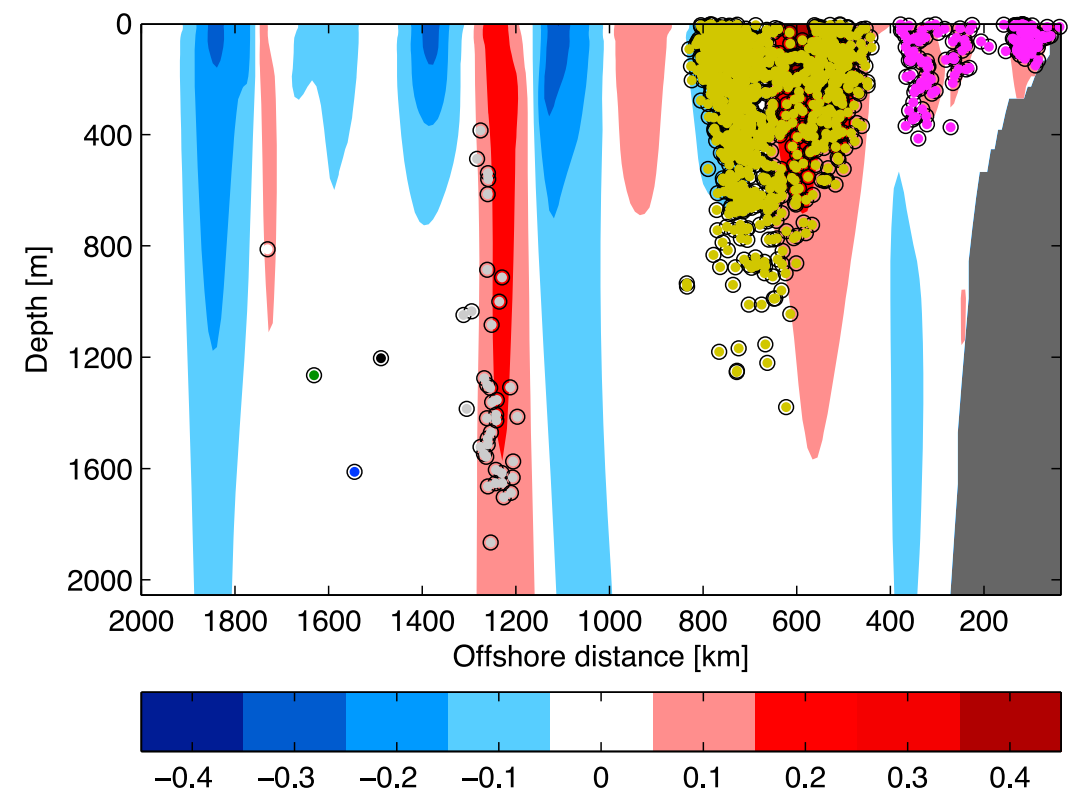

Figure 10. An example of the float clustering algorithm: The crossing locations of all 1121 floats that cross the Good Hope line for the last time on 28 November 1971 (colored dots). The blue and red patches denote the velocity perpendicular to the Good Hope line, in $\mathrm{m} \mathrm{s}^{-1}$. The clustering produces seven clusters, each denoted by a different color. This is a typical clustering at the Good Hope line, with one or two very large clusters (diameters of larger than $300 \mathrm{~km}$ and large amounts of floats) and a number of much smaller clusters.

vorticity and consequently a decrease in relative vorticity. This effect counteracts the decay of Agulhas cyclones, but may aid in the decay of Agulhas rings. The fast decay of Agulhas cyclones is even more remarkable in that respect.

[37] One may argue that, since only floats between $19^{\circ} \mathrm{E}$ and the Good Hope line are used in the analysis of the decay rate of relative vorticity, the results are biased toward floats that stay close to the Agulhas Current retroflection for a long time. The floats that are quickly advected over the Good Hope line in Agulhas rings are only taken into account for a short time in the analysis and this may affect the temporal evolution of the partitioning. However, the distribution of relative vorticity as the floats cross the Good Hope line (Table 1 and Figure 7) shows that the flux of relative vorticity over that line is much more toward water with low magnitude of relative vorticity than at $19^{\circ} \mathrm{E}$, and this 'Eulerian' result does not suffer from biases due to dawdling floats. Furthermore, the amount of floats that maintain their initial polarity (either cyclonic or anticyclonic) throughout the Cape Basin decays rapidly, while the amount of floats that loose their polarity increases in the first month (Figure 9) and shows a much slower decay after that.

\section{Change in Feature Size}

[38] The analysis of the change in relative vorticity at float locations between $19^{\circ} \mathrm{E}$ and the Good Hope line revealed that Agulhas leakage starts within water with anticyclonic and cyclonic relative vorticity, but that the water quickly mixes this relative vorticity away. After 10 months, values of relative vorticity are so low that the vast majority of floats cannot be considered inside eddies anymore. This raises the question in what kind of structures these floats are trapped then.

[39] There are at least three types of noneddy structures with which floats can be advected into the Atlantic Ocean, and they can be distinguished by their size. First of all, floats can be trapped in coherent filaments: small $(\sim 50 \mathrm{~km})$ structures that are the debris of Agulhas ring disintegration [Lutjeharms and Cooper, 1996; De Steur et al., 2004]. Secondly, floats can be advected in bulk by patches, larger coherent structures of water without significant rotation. And finally, floats may break away from coherent structures and get advected individually within the northwestward flow set by the South Atlantic Ocean subtropical gyre.

[40] To investigate how important each of these three noneddy structures are, the spatial scales associated with the leakage can be determined using a cluster analysis (see Appendix A for a discussion of how this is done). At each model snapshot, the floats crossing both $19^{\circ} \mathrm{E}$ and the Good Hope line are clustered according to their mutual distance (Figure 10). This means that floats which are close together will be in the same cluster, while floats which are far apart will be in different clusters. The result is that each float is assigned to a cluster, which may consist of a single float to several hundreds of floats. Floats in the same cluster belong to the same coherent feature, while floats in different clusters are in distinct coherent features.

[41] When only floats that cross $19^{\circ} \mathrm{E}$ south of $36^{\circ} \mathrm{S}$ are used, clusters that have components both north and south of $36^{\circ} \mathrm{S}$ are broken. This leads to erroneous clusterings. Therefore, all floats ending up in the Atlantic Ocean are considered in the clustering analysis. This is in contrast to the relative vorticity analysis of section 4 , where only floats that cross $19^{\circ} \mathrm{E}$ south of $36^{\circ} \mathrm{S}$ are taken into account. 

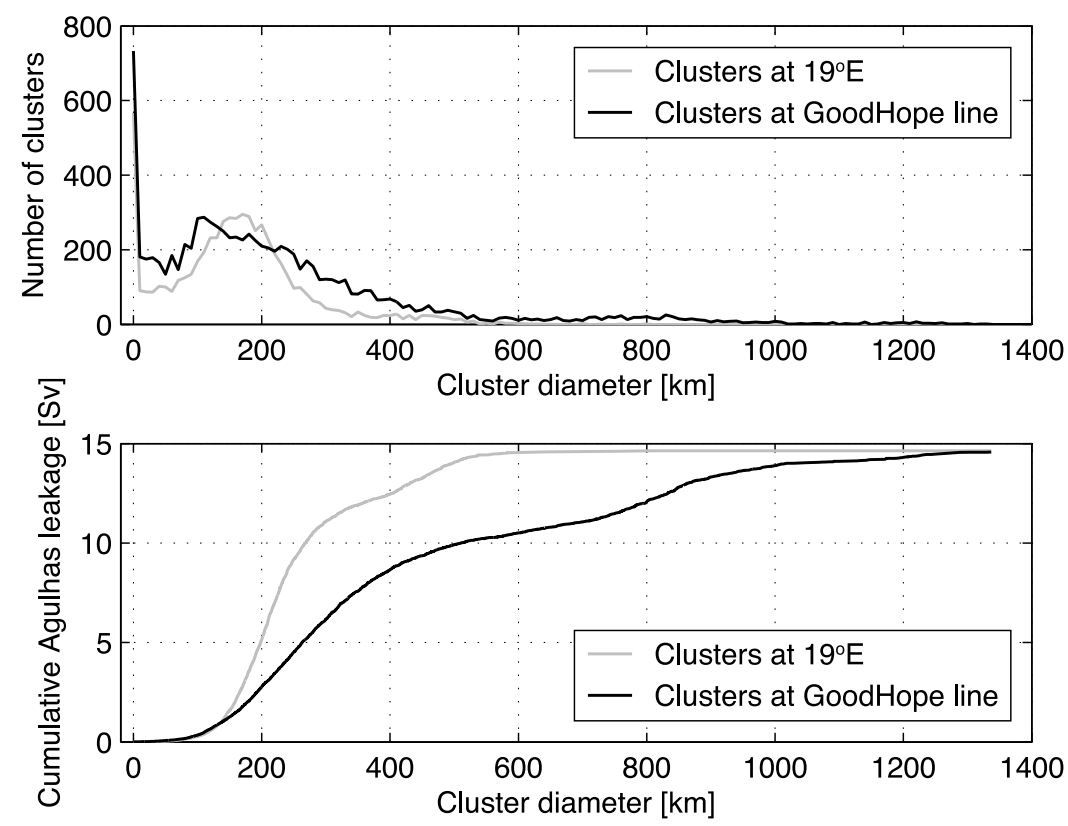

Figure 11. (top) The distribution of cluster radius, the largest horizontal distance between any two members in a cluster, for the clustering at $19^{\circ} \mathrm{E}$ (gray line) and at the Good Hope line (black line). The number of very small clusters $(<10 \mathrm{~km})$ is comparable at both sections. At $19^{\circ} \mathrm{E}$, there is a maximum around $180 \mathrm{~km}$ associated with the width of the Agulhas Current. At the Good Hope line, this peak has spread to both smaller clusters but also to much larger clusters. (bottom) The cumulative magnitude of Agulhas leakage as a function of cluster radius reveals that most leakage at $19^{\circ} \mathrm{E}$ is within clusters around $200 \mathrm{~km}$ in diameter. At the Good Hope line, however, most transport is bipartitioned in clusters with diameters around 300 and $850 \mathrm{~km}$. Apparently, some clusters break into smaller pieces, while other merge into much larger clusters.

[42] Near the Agulhas Current retroflection, at $19^{\circ} \mathrm{E}$, there are two peaks in the distribution of clusters based on their diameter (Figure 11). Many clusters are smaller than $10 \mathrm{~km}$. As these clusters represent a negligible amount of Agulhas leakage they are predominantly related to clusters containing only one float. The second peak lies around $180 \mathrm{~km}$, and this peak is probably related to the Agulhas Current core, which typically has such a width at $19^{\circ} \mathrm{E}$. Most of the Agulhas leakage transport is within clusters of diameters 180-300 km.

[43] At the Good Hope line, the number of very small clusters $(<10 \mathrm{~km})$ has not changed much. The peak at $180 \mathrm{~km}$, on the other hand, has been smeared out toward both smaller and larger clusters. Apparently, the vigorous mixing
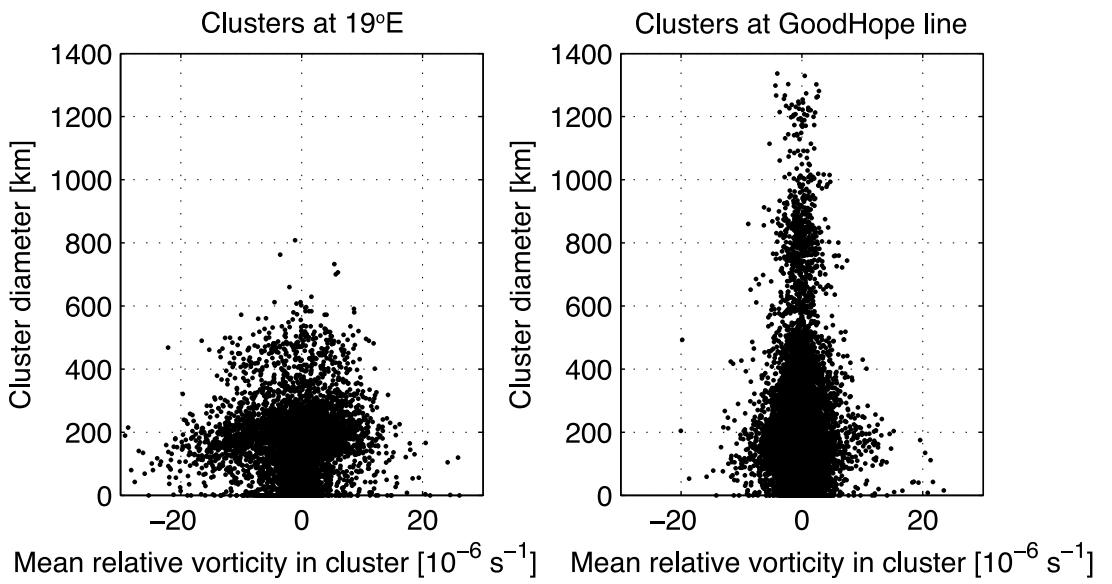

Figure 12. The diameter of the clusters as a function of the mean relative vorticity within these clusters (left) at $19^{\circ} \mathrm{E}$ and (right) at the Good Hope line. The magnitude of mean relative vorticity of the clusters is much larger at $19^{\circ} \mathrm{E}$ than at the Good Hope line. This result complements Figure 7, which showed (on a per float basis) the same collapse of relative vorticity. 


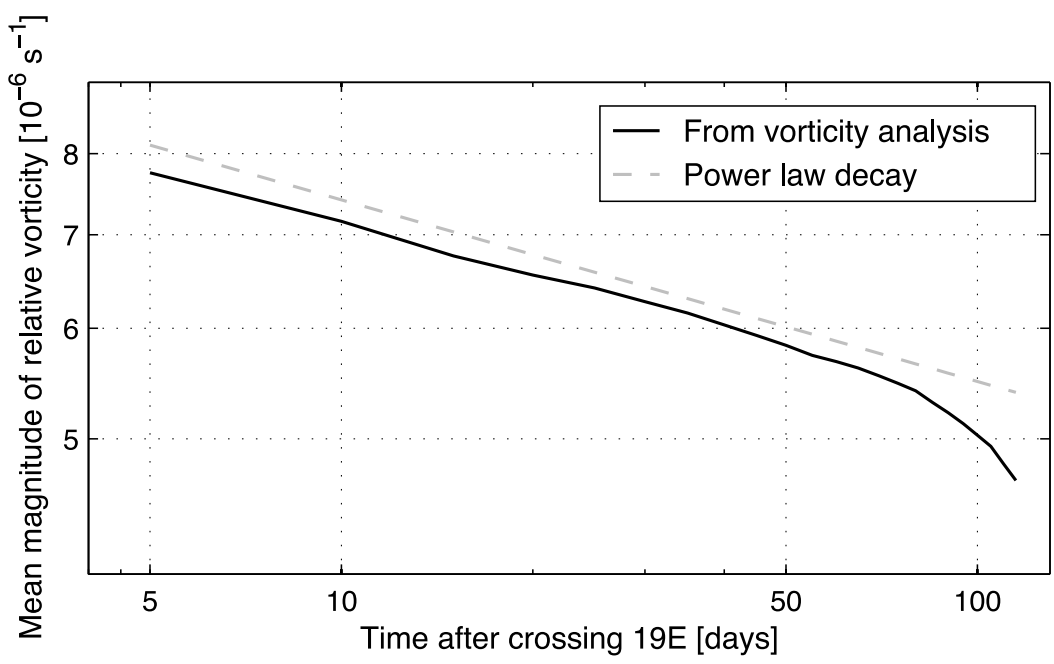

Figure 13. The decay of relative vorticity on a log-log scale, for the first 120 days after the floats have crossed $19^{\circ} \mathrm{E}$. The black line is similar to the black line of Figure 8, only on a different scale. This is done to highlight that in the early stages of decay the Agulhas leakage seems to behave like two-dimensional turbulence, where the decay of relative vorticity also obeys a power law [Clercx et al., 1999]. The gray dashed line is the $\xi=-0.13$ power law scaling.

in the Cape Basin does not only cause clusters to break into smaller filaments, but also to merge or deform into much larger clusters. The increase in the number of small clusters $(<150 \mathrm{~km})$ at the Good Hope line has a very limited effect on the amount of Agulhas leakage in these clusters (Figure 11 (bottom)). The largest change between $19^{\circ} \mathrm{E}$ and the Good Hope line is that larger clusters $(>200 \mathrm{~km})$ become more important.

[44] An analysis of the mean relative vorticity in the clusters shows that the magnitude of relative vorticity has decreased from $19^{\circ} \mathrm{E}$ to the Good Hope line (Figure 12). Near the Agulhas Current retroflection, the mean relative vorticity of large clusters is not very different from that of small clusters. At the Good Hope line, on the other hand, the large clusters have almost no mean relative vorticity, and only smaller clusters have some rotation. This result confirms the considerations on relative vorticity decay from section 4 .

[45] The small clusters $(<150 \mathrm{~km}$ in diameter) may be related to Agulhas rings and cyclones. Many of them have significant relative vorticity (Figure 12). A 100-150 km radius is also typical for an Agulhas ring in the real ocean [e.g., Van Aken et al., 2003]. The larger clusters, however, are not simply large rings. They have almost no relative vorticity, and therefore probably no expression in the sea surface height. These large clusters, which can be regarded as large patches of mixed Indian Ocean water, might therefore be difficult to observe in the real ocean, although they carry most of the Agulhas leakage transport over the Good Hope line.

\section{Comparison With the Decay of Two-Dimensional Turbulence}

[46] The increase in the number of large clusters with low relative vorticity may be related to concepts from twodimensional turbulence [e.g., Tennekes, 1978; Carnevale et al., 1991]. Unlike in three-dimensional turbulence, where vortices break into smaller vortices until they are dissipated by (molecular) viscosity, vortices in two-dimensional turbulence tend to merge into larger structures [Clercx et al., 1999]. These larger structures have a lower mean relative vorticity. This upward cascade in wavelengths might also be occurring in the Cape Basin, where the high relative vorticity eddies seem to merge into larger low relative vorticity patches.

[47] It is hard to quantify this cascade from the clustering analysis, but it can be done using the decay of the magnitude of relative vorticity of the individual floats (the data in Figure 8). When plotted on a log-log scale, the decay of the magnitude of relative vorticity in the first 100 days appears to behave as a power law (Figure 13). Such a power law is typically seen in turbulence decay [e.g., McWilliams, 1989; Maassen et al., 1999], where the relative vorticity as a function of time is of the form

$$
\zeta(t) \sim t^{\xi}
$$

[48] In this case, the fitting parameter of the power law is $\xi=-0.13$. This is larger than the fitting parameter in freely decaying two-dimensional turbulence, where the value is typically -0.30 [e.g., Clercx et al., 1999]. That might have to do with the large discrepancy between idealized turbulence studies and the representation of turbulence in this numerical ocean model. Most studies of two-dimensional turbulence are based on homogeneous and isotropic conditions for the flow. In the AG01 model, however, the flow is forced by wind patterns and steered by the bathymetry. The circulation in the model can therefore not be considered isotropic nor homogeneous. Furthermore, the spatial resolution and Reynolds parameter regime of even this state-ofthe-art numerical ocean model is far from what is used in decaying turbulence studies. Nevertheless, it is interesting to 
see that the decay of relative vorticity in the model behaves like a power law.

\section{Conclusions and Discussion}

[49] Using numerical float trajectories in a high-resolution two-way nested regional ocean model, we have investigated the decay of Agulhas rings and cyclones close to the Agulhas Current retroflection. It appears that between the Agulhas Current retroflection and the Good Hope line in the Cape Basin, the floats that were initially in Agulhas rings and cyclones are quickly expelled into large patches with low relative vorticity. This fast decay of eddies near the Agulhas Current retroflection can explain the large discrepancy between studies trying to group Agulhas leakage in fractions by Agulhas rings, Agulhas cyclones, and other forms of leakage. It appears that the result of such grouping methods is sensitive to the location where the grouping is performed.

[50] The decay of eddies was investigated using two different methods: by assessing the relative vorticity of the water around a float, and by employing a cluster analysis. The results of these methods are complementary. In both methods it appears that, when floats move through the Cape Basin from the Agulhas Current retroflection to the Good Hope line, they quickly loose their relative vorticity. When the floats cross the Cape Basin, the bulk of leakage is in large-scale patches $(200-1000 \mathrm{~km}$ in diameter) with low relative vorticity. Similar behavior is seen in the decay of two-dimensional turbulence, where there is an energy cascade to the larger scales.

[51] The comparable cross-current distributions of floats ending in the Atlantic Ocean and floats ending in the Indian Ocean suggests that float fate is predominantly determined by the moment when floats get through the retroflection area, and whether they are in a ring shedding event. Only for a small portion of the Agulhas leakage transport (2 Sv) is the fate determined more upstream as floats on the Agulhas Bank have a much higher chance of ending in the Atlantic Ocean through the Good Hope Jet.

[52] The analysis in this study has been performed in a Eulerian way, by assessing the relative vorticity of the water in which the numerical floats are advected into the Atlantic Ocean. Another way to study the features in which Agulhas leakage enters the Atlantic Ocean is by determining the looping behavior of the numerical floats [Doglioli et al., 2006; Richardson, 2007]. The data set used here is designed for a Eulerian analysis of relative vorticity, with large amounts of floats on a high-resolution spatial grid, reducing interpolation errors. The cost of this design is that float locations are stored only every 5 days. This resolution is too low for a loop analysis approach, as it means that the time resolution is in the same order as the rotation time of a float in an eddy and that is why looping behavior analysis could not be performed in this study.

[53] Furthermore, assessing the looping orientation of a float requires a path length of at least a few rotation periods. This means that fast changes in the decay of Agulhas rings and cyclones, one of the key questions addressed in this study, cannot be resolved by studying spin characteristics. The fact that the studies of Doglioli et al. [2006], Richardson [2007], and this study come to very similar conclusions while using different methods with different amounts of floats at different spatial and temporal resolution makes the results of all of these studies more convincing. In that sense, these three studies can reinforce each other.

[54] One important result from the study of Richardson [2007], using real ocean floats to study among others the paths of Agulhas rings and cyclones, is that most Agulhas cyclones move on a southwestward course. The cyclones then disintegrate over rough topography southwest of the Agulhas Current retroflection. It is important to note that due to the setup of the experiments here, where only floats are taken into account that end up in the Atlantic Ocean, these southwestward moving Agulhas cyclones are not captured in the data set. It appears that most of the Agulhas cyclone debris in the model is advected eastward by the Agulhas Return Current or the Antarctic Circumpolar Current, never crossing the Good Hope line. The Agulhas cyclones which are discussed here predominantly form on the inshore side of the Agulhas Current and move westward from there, similar to the trajectories shown by Lutjeharms et al. [2003].

[55] The quick loss of relative vorticity by Agulhas leakage is probably controlled by changes in the potential vorticity balance. Potential vorticity is conserved, but relative vorticity can be converted to other terms in the balance, such as stretching. Boudra and Chassignet [1988] have extensively studied this, but in a simple model. Ideally, this conversion between the terms in the vorticity balance would be studied in a high-resolution model such as the one used here. Combining the balance terms with Lagrangian float trajectories could yield more insight on why the loss of relative vorticity is so fast in the Agulhas Current retroflection region. Work in that direction is in progress.

\section{Appendix A}

[56] The spatial scale of the coherent features in which the floats cross the Good Hope line (section 5) is investigated using a cluster analysis. This is done to assure an objective assessment of the size of the features, under the assumption that floats which are close together when they cross the Good Hope line are in the same feature and cluster.

[57] The clustering analysis is performed using a minimum distance approach. At the start of the analysis, each cluster consists of exactly one float. Then, the two clusters that are closest together are merged. This merging is repeated until all floats are in one cluster. The merging steps can be visualized in a dendrogram, with the distance at which two clusters are merged on the ordinate. The clusters are then the connected branches of a horizontal cross section through the dendrogram at a particular height. Such a set of all clusters is called a clustering.

[58] In advance, it is unknown how many clusters of floats there are in any snapshot. To determine the optimum number of clusters, clusterings with 1-10 clusters are computed. A skill is associated with each of these 10 tested clusterings, and the clustering with the highest skill is chosen.

[59] The skill is defined as the mean of the silhouette scores of the clustering [Rousseeuw, 1987]. The silhouette score of a float represents that float's distance to floats within its cluster compared to the distance to floats in other clusters (Figure A1). Two quantities are computed for each float $i$ in a certain cluster $A: a(i)$ the average horizontal 


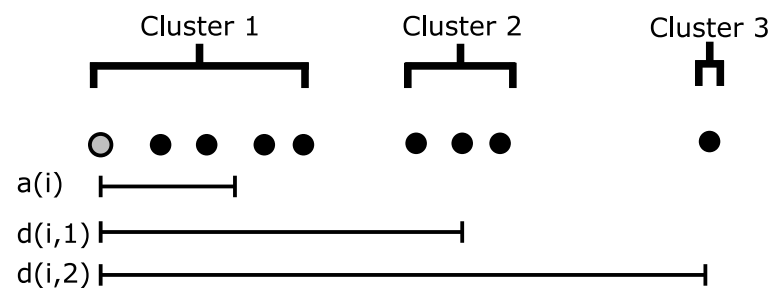

Figure A1. An example of the silhouette score algorithm, for nine floats within three clusters. For a certain float $i$ (the gray circle), the mean distance to all other floats within its own cluster is computed as $a(i)$. The mean distance to all floats within each of the other clusters $C$ is computed as $d(i$, $C)$. The silhouette score $s(i)$ of the float is then computed by equations (A1) and (A2). In this example, the silhouette score of float $i$ is approximately 0.6 . This procedure for calculating silhouette scores was proposed by Rousseeuw [1987].

distance between float $i$ and all other floats in its cluster $A$; and for all other clusters $d(i, C)$ the average horizontal distance between float $i$ and all floats in cluster $C$. The cluster closest to $i$ is selected and denoted by

$$
b(i)=\min _{C \neq A} d(i, C)
$$

and the silhouette score for float $i$ is then defined as

$$
s(i)=\frac{b(i)-a(i)}{\max \{a(i), b(i)\}} .
$$

A silhouette score of +1 means that the float is indisputably within the correct cluster and a silhouette score of -1 means that it has a better place in another cluster. Application of this approach to the float data set results in clusterings with typically four to five clusters and a mean silhouette score of 0.81 .

[60] Ideally, the clustering algorithm would be applied to the entire data set at once, rather than for each snapshot individually. However, this involves computation of the distances between all float crossing locations, resulting in a $1.9 \times 10^{6}$ by $1.9 \times 10^{6}$ matrix. This is computationally unfeasible, and therefore the clustering has been limited to model snapshots. At any snapshot there are in the order of 500 float crossings, which results in a much better manageable $500 \times 500$ distances matrix.

[61] Acknowledgments. E.v.S. is sponsored by the SRON User Support Programme under grant EO-079, with financial support from the Netherlands Organization for Scientific Research, NWO. P.J.v.L. is partly supported by the MERSEA project of the European Commission under contract SIP3-CT-2003-502885. Model and float integrations have been performed at the Höchstleistungsrechenzentrum Stuttgart (HLRS). We thank an anonymous reviewer and P. L. Richardson for their very useful comments.

\section{References}

Bang, N. D., and W. R. H. Andrews (1974), Direct current measurements of a shelf-edge frontal jet in the southern Benguela system, J. Mar. Res., 32, 405-417.

Beal, L. M., and H. L. Bryden (1999), The velocity and vorticity of the Agulhas Current at $32^{\circ} \mathrm{S}, \mathrm{J}$. Geophys. Res., 104, 5151-5176.

Beal, L. M., T. K. Chereskin, Y. D. Lenn, and S. Elipot (2006), The sources and mixing characteristics of the Agulhas Current, J. Phys. Oceanogr., 36, 2060-2074.
Beismann, J. O., R. H. Käse, and J. R. E. Lutjeharms (1999), On the influence of submarine ridges on translation and stability of Agulhas rings, J. Geophys. Res., 104, 7897-7906.

Biastoch, A., C. W. Böning, and J. R. E. Lutjeharms (2008a), Agulhas leakage dynamics affects decadal variability in Atlantic overturning circulation, Nature, 456, 489-492.

Biastoch, A., J. R. E. Lutjeharms, C. W. Böning, and M. Scheinert (2008b), Mesoscale perturbations control inter-ocean exchange south of Africa, Geophys. Res. Lett., 35, L20602, doi:10.1029/2008GL035132.

Biastoch, A., L. M. Beal, J. R. E. Lutjeharms, and T. G. D. Casal (2009), Variability and coherence of the Agulhas Undercurrent in a highresolution ocean general circulation model, J. Phys. Oceanogr., 39, 2417-2435.

Blanke, B., and S. Raynaud (1997), Kinematics of the Pacific Equatorial Undercurrent: An Eulerian and Lagrangian approach from GCM results, J. Phys. Oceanogr., 27, 1038-1053.

Boebel, O., J. R. E. Lutjeharms, C. Schmid, W. Zenk, T. Rossby, and C. N. Barron (2003), The Cape Cauldron, a regime of turbulent inter-ocean exchange, Deep Sea Res. Part II, 50, 57-86.

Boudra, D. B., and E. P. Chassignet (1988), Dynamics of Agulhas retroflection and ring formation in a numerical model. Part I: The vorticity balance, J. Phys. Oceanogr., 18, 280-303.

Bryden, H. L., L. M. Beal, and L. M. Duncan (2005), Structure and transport of the Agulhas Current and its temporal variability, J. Oceanogr., 61, 479-492.

Byrne, D. A., and J. L. McClean (2008), Sea level anomaly signals in the Agulhas Current region, Geophys. Res. Lett., 35, L13601, doi:10.1029/ 2008GL034087.

Byrne, D. A., A. L. Gordon, and W. F. Haxby (1995), Agulhas eddies: A synoptic view using Geosat ERM data, J. Phys. Oceanogr., 25, 902-917.

Carnevale, G. F., J. C. McWilliams, Y. Pomeau, J. B. Weiss, and W. R. Young (1991), Evolution of vortiex statistics in two-dimensional turbulence, Phys. Rev. Lett., 66, 2735-2737.

Clercx, H. J. H., S. R. Maassen, and G. J. F. Van Heijst (1999), Decaying two-dimensional turbulence in square containers with no-slip or stressfree boundaries, Phys. Fluid., 11, 611-626.

Debreu, L., C. Vouland, and E. Blayo (2008), AGRIF: Adaptive grid refinement in Fortran, Comput. Geosci., 34, 8-13.

De Ruijter, W. P. M., and D. B. Boudra (1985), The wind-driven circulation in the South Atlantic-Indian Ocean-Part I. Numerical experiments in a one-layer model, Deep Sea Res., 32, 557-574.

De Ruijter, W. P. M., A. Biastoch, S. S. Drijfhout, J. R. E. Lutjeharms, R. P. Matano, T. Pichevin, P. J. Van Leeuwen, and W. Weijer (1999), Indian-Atlantic interocean exchange: Dynamics, estimation, and impact, J. Geophys. Res., 104, 20,885-20,910.

De Steur, L., P. J. Van Leeuwen, and S. S. Drijfhout (2004), Tracer leakage from modeled Agulhas rings, J. Phys. Oceanogr., 34, 1387-1399.

Doglioli, A. M., M. Veneziani, B. Blanke, S. Speich, and A. Griffa (2006), A Lagrangian analysis of the Indian-Atlantic interocean exchange in a regional model, Geophys. Res. Lett., 33, L14611, doi:10.1029/ 2006GL026498.

Doglioli, A. M., B. Blanke, S. Speich, and G. Lapeyre (2007), Tracking coherent structures in a regional ocean model with wavelet analysis: Application to Cape Basin eddies, J. Geophys. Res., 112, C05043, doi:10.1029/2006JC003952.

Donners, J., and S. S. Drijfhout (2004), The lagrangian view of South Atlantic interocean exchange in a global ocean model compared with inverse model results, J. Phys. Oceanogr., 34, 1019-1035.

Fennel, W. (1999), Theory of the Benguela upwelling system, J. Phys. Oceanogr., 29, 177-190.

Feron, R. C. V., W. P. M. De Ruijter, and D. Oskam (1992), Ring shedding in the Agulhas Current System, J. Geophys. Res., 97, 9467-9477.

Gordon, A. L. (1985), Indian-Atlantic transfer of thermocline water at the Agulhas retroflection, Science, 227, 1030-1033.

Gordon, A. L. (1986), Interocean exchange of thermocline water, J. Geophys. Res., 91, 5037-5046.

Gordon, A. L., K. T. Bosley, and F. Aikman III (1995), Tropical Atlantic water within the Benguela upwelling system at $27^{\circ} \mathrm{S}$, Deep Sea Res. Part I, 42, 1-12.

Knorr, G., and G. Lohmann (2003), Southern Ocean origin for the resumption of Atlantic thermohaline circulation during deglaciation, Nature, 424, 532-536.

Large, W. G., and S. G. Yeager (2004), Diurnal to decadal global forcing for ocean and sea-ice models: The data sets and flux climatologies, Tech. Note NCAR/TN-460+STR, Natl. Cent. for Atmos. Res., Boulder, Colo. Lutjeharms, J. R. E. (2006), The Agulhas Current, Springer, Berlin.

Lutjeharms, J. R. E., and J. Cooper (1996), Interbasin leakage through Agulhas Current filaments, Deep Sea Res. Part I, 43, 213-238. 
Lutjeharms, J. R. E., and H. R. Roberts (1988), The Natal Pulse: An extreme transient on the Agulhas Current, J. Geophys. Res., 93, 631-645.

Lutjeharms, J. R. E., and R. C. Van Ballegooyen (1988), The retroflection of the Agulhas Current, J. Phys. Oceanogr., 18, 1570-1583.

Lutjeharms, J. R. E., O. Boebel, and H. T. Rossby (2003), Agulhas cyclones, Deep Sea Res. Part I, 50, 13-34.

Maassen, S. R., H. J. H. Clercx, and G. J. F. Van Heijst (1999), Decaying quasi-2d turbulence in a stratified fluid with circular boundaries, Europhys. Lett., 46, 339-345.

Madec, G. (2006), NEMO ocean engine, Note Pole Model. 27, Inst. PierreSimon Laplace, Palaiseau, France.

Matano, R. P., and E. J. Beier (2003), A kinematic analysis of the Indian/ Atlantic inter-ocean exchange, Deep Sea Res. Part II, 50, 229-250.

McWilliams, J. C. (1989), Statistical properties of decaying geostrophic turbulence, J. Fluid Mech., 198, 199-230.

Ou, H. W., and W. P. M. De Ruijter (1986), Separation of an inertial boundary current from a curved coastline, J. Phys. Oceanogr., 16, 280-289.

Peeters, F. J. C., R. Acheson, G. A. Brummer, W. P. M. De Ruijter, R. R. Schneider, G. M. Ganssen, E. Ufkes, and D. Kroon (2004), Vigorous exchange between the Indian and Atlantic oceans at the end of the past five glacial periods, Nature, 430, 661-665.

Richardson, P. L. (2007), Agulhas leakage into the Atlantic estimated with subsurface floats and surface drifters, Deep Sea Res. Part I, 54, 1361-1389.

Rio, M. H., and F. Hernandez (2004), A mean dynamic topography computed over the world ocean from altimetry, in situ measurements, and a geoid model, J. Geophys. Res., 109, C12032, doi:10.1029/ 2003JC002226.

Rousseeuw, P. J. (1987), Silhouettes: A graphical aid to the interpretation and validation of cluster analysis, J. Comput. Appl. Math., 20, 53-65.

Schouten, M. W., W. P. M. De Ruijter, P. J. Van Leeuwen, and J. R. E. Lutjeharms (2000), Translation, decay and splitting of Agulhas rings in the southeastern Atlantic Ocean, J. Geophys. Res., 105, 21,913-21,925.

Speich, S., B. Blanke, P. De Vries, S. S. Drijfhout, K. Döös, A. Ganachaud, and R. Marsh (2002), Tasman leakage: A new route in the global ocean conveyor belt, Geophys. Res. Lett., 29(10), 1416, doi:10.1029/ $2001 \mathrm{GL} 014586$.
Swart, S., S. Speich, I. J. Ansorge, G. J. Goni, S. Gladyshev, and J. R. E. Lutjeharms (2008), Transport and variability of the Antarctic Circumpolar Current south of Africa, J. Geophys. Res., 113, C09014, doi:10.1029/ $2007 \mathrm{JC} 004223$

Tennekes, H. (1978), Turbulent flow in two and three dimensions, Bull. Am. Meteorol. Soc., 59, 22-28.

Treguier, A. M., O. Boebel, C. Barnier, and G. Madec (2003), Agulhas eddy fluxes in a $1 / 6^{\circ}$ Atlantic model, Deep Sea Res. Part II, 50, 251-280.

Van Aken, H. M., A. K. Van Veldhoven, C. Veth, W. P. M. De Ruijter, P. J. Van Leeuwen, S. S. Drijfhout, C. C. Whittle, and M. Rouault (2003), Observations of a young Agulhas ring, Astrid, during MARE in March 2000, Deep Sea Res. Part II, 50, 167-195.

Van Leeuwen, P. J., W. P. M. De Ruijter, and J. R. E. Lutjeharms (2000), Natal pulses and the formation of Agulhas rings, J. Geophys. Res., 105, 6425-6436.

Van Sebille, E., A. Biastoch, P. J. Van Leeuwen, and W. P. M. De Ruijter (2009a), A weaker Agulhas Current leads to more Agulhas leakage, Geophys. Res. Lett., 36, L03601, doi:10.1029/2008GL036614.

Van Sebille, E., P. J. Van Leeuwen, A. Biastoch, C. N. Barron, and W. P. M. De Ruijter (2009b), Lagrangian validation of numerical drifter trajectories using drifting buoys: Application to the Agulhas region, Ocean Model., 29, 269-276.

Weijer, W., W. P. M. De Ruijter, A. Sterl, and S. S. Drijfhout (2002), Response of the Atlantic overturning circulation to South Atlantic sources of buoyancy, Global Planet. Change, 34, 293-311.

A. Biastoch, Leibniz Institute of Marine Sciences, University of Kiel, Düsternbrooker Weg 20, D-24105, Kiel, Germany.

W. P. M. de Ruijter, Institute for Marine and Atmospheric Research, Utrecht University, Princetonplein 5, Utrecht NL-3584 CC, Netherlands.

P. J. van Leeuwen, Department of Meteorology, University of Reading, Earley Gate, PO Box 243, Reading RG6 6BB, UK.

E. van Sebille, Rosenstiel School of Marine and Atmospheric Science, University of Miami, 4600 Rickenbacker Cswy., Miami, FL 33149, USA. (evansebille@rsmas.miami.edu) 